\title{
REFORMA EDUCACIONAL E PRÁTICA DOCENTE: O DISCURSO SOBRE A APROPRIAÇÁO DOS SEUS FUNDAMENTOS NA ESCOLA
}

\author{
EDUCATIONAL REFORM AND TEACHING PRACTICE: THE SPEECH \\ ABOUT THE APPROPRIATION OF ITS FOUNDATIONS AT SCHOOL
}

\author{
Valéria Andrade Silva \\ Doutoranda em Educaçáo PPGE-UNINOVE \\ São Paulo, SP - Brasil \\ valeria_dot_com@yahoo.com.br \\ Miguel Henrique Russo \\ Professor do PPGE-UNINOVE \\ São Paulo, SP - Brasil \\ mh.russo@uol.com.br
}

\begin{abstract}
Resumo: Neste texto sintetizamos dados e discussóes de uma pesquisa realizada em uma escola da rede estadual de ensino paulista para apurar como se deu a apropriaçáo, pelos professores, dos fundamentos e das ideias centrais da reforma educacional promovida pelo governo Serra através de um Plano de Ação acompanhado pelo programa "São Paulo faz escola" que trata da dimensão curricular. A coleta de dados envolveu entrevistas, observaçôes e análise documental dos Planos de Ensino. Os resultados revelam que os docentes fizeram uma apropriação bastante parcial dos conceitos fundamentais da proposta e que desenvolvem uma prática que confirma o pressuposto de que o currículo é a ação desenvolvida na prática escolar mediada pela apropriação que os docentes fazem das ideias dos reformadores.
\end{abstract}

Palavras-Chave: Apropriação e objetivação. Prática escolar. Proposta curricular. Reforma educacional.

Abstract: In this text we summarize the data and discussions of an investigation made at a São Paulo public state school which aimed to verify how teachers have appropriated the foundations and central ideas of the educational reform promoted during Serra's government through an Action Plan followed by the program "São Paulo faz escola" which refers to the curricular dimension of the reform. The data were collected from interviews, observations and documental analysis of teaching plans. The results revealed that teachers made quite a partial appropriation of the conceptual basis of the curricular proposal and that their practice confirms the tenet of curriculum being the action developed in the school practice mediated by the teachers' appropriation of the reformers ideas.

KeY words: Appropriation and objectification. Curricular proposal. Educational reform. School practice. 


\section{Introduçáo}

O objetivo deste trabalho é apresentar o resultado de uma pesquisa realizada, em 2010, em uma escola pública da rede estadual paulista para identificar as consequências da implantação da reforma do ensino realizada no governo Serra. A pesquisa com foco nas mudanças da prática docente e sua relação com a utilização do material didático do programa "São Paulo faz escola" - uma das ações centrais da reforma da educação em curso, no Estado de São Paulo -, teve como sujeitos os professores da disciplina de Língua Portuguesa, do ciclo II do Ensino Fundamental, de uma unidade escolar localizada em bairro da zona oeste da Capital paulista e utilizou como instrumentos de coleta de dados a entrevista com aqueles professores e com o coordenador pedagógico e a análise dos Planos de Ensino da disciplina em questão.

Nosso pressuposto é o de que a ressignificação do currículo realizada pelos professores para orientar a sua prática decorre da modelação que se realiza por meio da apropriaçáo dos pressupostos teóricos da Proposta Curricular, mediada pelo que entendemos serem seus mecanismos de controle (a estratégia de apresentação da Proposta Curricular aos professores; a padronizaçáo do material didático de apoio; o papel atribuído ao Professor Coordenador e a política de bônus articulada com a avaliação externa) e pelos condicionamentos escolares prefigurados pelo institucional, pela organizaçáo e pela cultura escolar, os quais determinarão as condiçóes concretas de apropriação e objetivação do currículo prescrito.

Com essa perspectiva abordaremos, na primeira parte, o modo como compreendemos o processo de apropriação e objetivação de propostas curriculares e, na segunda, apresentaremos os mecanismos de controle instituídos pelo programa "São Paulo faz escola". Na parte final, expomos os dados da pesquisa, identificados na prática escolar dos professores, principalmente aqueles relacionados com a padronização do material didático, que revelam como eles se apropriaram da nova Proposta Curricular. 


\section{O processo de apropriaçáo e objetivação de propostas curriculares}

As reformas dos sistemas educativos e das instituições de ensino não se restringem apenas às transformaçóes amplas e estruturais ou, meramente, às mudanças pontuais e limitadas. As mudanças circunscritas ao âmbito organizacional e curricular guardam relaçôes com os determinantes políticos, sociais e econômicas externos à escola. Assim, as reformas curriculares implicam em uma série de modificaçôes que afetam os processos educativos e a vida das instituições escolares (VIÑAO FRAGO, 2006).

Sacristán (2000) entende que a organização do currículo faz parte da intervenção do Estado no arranjo da vida social. Na medida em que as reformas curriculares implicam em seleção do conhecimento, elas afetam, fortemente, o mercado de trabalho, dado que ele é essencial a qualquer setor produtivo e profissional. Consequentemente, para esse autor, "ordenar a distribuição do conhecimento através do sistema educativo é um modo não só de influir na cultura, mas também em toda a ordenação social e econômica da sociedade" (SACRISTÁN, 2000, p. 108).

As reformas não são capazes de produzir mudanças ou transformaçôes bruscas nas culturas escolares, justamente porque é no processo de reprodução desta que ocorre seu processo de transformação (FARIA FILHO, 2007), ou seja, os sujeitos da escola objetivam em sua prática a cultura escolar por eles apropriada e reproduzem uma continuidade na qual é possível observar inovaçóes produzidas por pequenas modificações nas rotinas, hábitos e padrôes existentes (POPKEWITZ, 1997) que, ao largo do tempo, transformarão a cultura escolar.

As transformações produzidas pelas reformas na prática escolar dependem não só dos fundamentos que as orientam ou das intençôes dos reformadores, mas, principalmente, de como estes são apropriados e objetivados pelos sujeitos daquelas práticas. Entendemos, assim, que o currículo ganha materialidade e significação por meio dos processos de apropriação e objetivação daquilo que propôe, ou seja, o currículo é aquele que se realiza na prática escolar concreta podendo refletir, ou não, a intencionalidade dos seus formuladores, os reformadores. 
O professor não escolhe as condições para desenvolver seu trabalho, mas possui a capacidade de modelar o currículo e ressignificá-lo em sua prática docente, o que lhe permite atuar com certa autonomia, mesmo que diminuta, dentro dos limites determinados pelos fatores que condicionam a prática escolar. Dado que "qualquer idéia que se pretenda implantar na prática passa pela sua personalização nos professores, isto é, por algum modo de introjeção em seus esquemas de pensamento e comportamento" (SACRISTÁN, 2000, p.178), o professor atua como mediador decisivo na ressignificação do currículo prescrito e na reelaboração da prática pressuposta pelo currículo imposto de fora.

Os princípios e fundamentos centrais das propostas curriculares se apresentam como um fim a ser realizado por meio da prática escolar. Os fatores condicionantes da prática medeiam o processo de apropriação do currículo pelos professores ao constituírem o contexto escolar, do qual "[...] emerge o horizonte de possibilidades produzido pela síntese das dimensões institucional, organizacional e cultural específicas da escola" (SILVA JR.; FERRETTI, 2004, p. 77).

Já a prática escolar como atividade prática e, especialmente, a prática docente como práxis individual, de acordo com Sánchez Vázquez (2007), são inseparáveis de uma posição teleológica ou, em outras palavras, de fins traçados pela consciência e que se apresentam em um processo que só termina quando o fim ou resultado ideal se concretiza em um produto real, depois de sofrer mudanças impostas pelas exigências da realidade, no caso, do contexto escolar.

$\mathrm{Na}$ etapa de modelação do currículo pelos professores, momento em que predomina a apropriaçáo, o fim ou produto ideal vai sofrendo modificaçóes determinadas pelas exigências das condiçóes materiais, porém ainda é apenas potência que pode ou não vir a ser objetivada. "Nãorealizado o fim posto, a apropriaçáo reduz-se ao plano da consciência e não possibilita a complexificação da sociabilidade humana, e menos ainda da objetividade social, podendo, no entanto, aumentar o conhecimento do indivíduo sobre aquele objeto da sua prática” (SILVA JR.; FERRETTI, 2004, p. 88).

Em sendo objetivado em um segundo momento da prática, o currículo ganha materialidade como fim ou pôr teleológico do qual se pode 
abstrair a apropriação realizada. A objetivação, de acordo com Silva Jr. e Ferretti (2004, p. 91) é

[...] o momento do trabalho e da prática social em que a teleologia, e nela a apropriação, tornam-se causalidade posta pelo ser humano. ... A objetivação é a articulação da teleologia com a materialidade da objetividade social. Nesse momento da prática - a objetivação - o ser social incorpora muitas generalidades em-si, resultado de práticas sociais que já foram realizadas na história humana e encontram-se à disposição na natureza e na objetividade social.

Faria Filho (2007) aponta que as reformas educativas representam uma disputa pela imposição de projetos culturais, dentro do processo de escolarização e que o sucesso de uma reforma depende principalmente de sua capacidade de deslocar os eixos das culturas escolares, criando oportunidades de produzir novos sentidos e significados de escolarização. Para este autor, "o fracasso ou não das reformas educativas não pode de forma alguma ser buscado ou explicado apenas pela maior ou menor eficácia das mesmas em resolver os problemas que atacar" (FARIA FILHO, 2007, p. 203).

Pelas mudanças curriculares, o poder central de um país constrói a positividade de uma reforma muito mais ampla que a dos currículos, visando sua legitimação. As práticas curriculares anteriores à reforma são negadas e/ou criticadas como desatualizadas, de forma a instituir o discurso favorável ao que será implantado: mudanças educacionais visando à constituiçấo de distintas identidades pedagógicas consideradas necessárias ao projeto político-social escolhido (LOPES, 2004, p. 110).

Sacristán (2000, p. 151) afirma que "entre os professores e o currículo prescrito em seus traços mais gerais se situam seus agentes apresentadores”. Para ele, as prescriçóes costumam ser muito genéricas, não sendo suficientes para orientar a prática educativa em sala de aula. Por isso, as 
diferentes instâncias elaboram uma série de meios para traduzir o significado e os conteúdos do currículo prescrito para os professores, tendo o livro-texto, o papel mais decisivo neste sentido.

Corroborando esta influência do material didático sobre a prática docente, registrada por Sacristán, constatamos que, na reforma em estudo, os Cadernos do Aluno, de Língua Portuguesa, orientam a seleção dos conteúdos e organizam sua sequência, o que anteriormente era feito pelo livro didático que, por ora, apenas complementa alguns pontos já presentes nos Cadernos do Aluno e do Professor, principalmente, com exercícios de fixação de conteúdo dos temas e dos tópicos de gramática.

Em síntese, o conjunto de contribuiçóes acima selecionadas nos ajuda a reafirmar nossa posição teórico-metodológica de que o currículo concreto para ser apreendido requer que se vá ao empírico e que se o submeta a um processo de reflexão crítica que possa revelar suas contradiçóes a partir das quais seja possível avançar na sua compreensão e apropriação.

\section{Os mecanismos de controle do programa "Sáo Paulo faz escola"}

O programa "São Paulo faz escola", fundamentado nas ideias da denominada Pedagogia das Competências, foi lançado em 2007, pela então secretária de Educação do governo Serra, Professora Maria Helena Guimaráes de Castro, com o objetivo anunciado de mudar o perfil da rede escolar e os indicadores da educação paulista, que se encontravam entre os piores do país. Em 2009, ocorreu a substituição da secretária pelo ex-ministro da Educação Paulo Renato Souza que deu continuidade aos projetos iniciados na gestão da ex-secretária.

Revelando a intenção de disseminar determinado discurso para a educação, no documento geral de Apresentação da Proposta Curricular, a SEE-SP afirma que o referido programa é um esforço que lhe cabe, enquanto condutora de políticas educacionais, para concretizar no cotidiano escolar propostas curriculares próprias e específicas para a rede estadual paulista e que estejam pautadas nas Diretrizes e Parâmetros Nacionais. Com esse sentido afirma que: 
Cabe às instâncias condutoras da política educacional nos estados e nos municípios elaborar, a partir das Diretrizes e dos Parâmetros Nacionais, Propostas Curriculares próprias e específicas, prover os recursos humanos, técnicos e didáticos para que as escolas, em seu projeto pedagógico, estabeleçam os planos de trabalho que, por sua vez, farão das propostas currículos em ação - como no presente esforço desta Secretaria (SEE-SP, 2008a, p. 13).

O conjunto de açóes previsto para a implementação do programa "São Paulo faz escola" se destina à organização didática das unidades escolares, às atribuiçóes das funçóes dos profissionais envolvidos no processo educativo e à fixaçáo de procedimentos didático-pedagógicos relativos ao funcionamento das escolas e do currículo. Para a apresentação de sua proposta curricular, a SEE-SP utilizou diferentes meios, com destaque para os Cadernos do Professor e Cadernos do Aluno que, como materiais didáticos, podem exercer maior influência sobre a prática do professor.

Esta reforma também institui outros mecanismos de controle além do currículo único e padronizado: o papel do Professor Coordenador Pedagógico e a avaliação externa vinculada à política de bônus.

Segundo o Caderno do Gestor, dentre as dez metas definidas no Plano Político Educacional do Governo do Estado de São Paulo, quatro (metas 2, 3, 4 e 5) estão diretamente relacionadas com a função do Professor Coordenador visando melhorar a aprendizagem dos alunos e aumentar em $10 \%$ os indicadores do Ensino Fundamental e Médio nas avaliaçóes externas.

Na etapa inicial de implantação da Proposta Curricular foi atribuída ao Professor Coordenador Pedagógico a tarefa de "identificar as tensóes e criar consensos" na escola. No Caderno do Gestor há um reforço da necessidade da criação de consensos por meio da assimilação das ideias propostas pela Secretaria como um caráter formativo da capacitação em serviço.

A Proposta Curricular tem seus princípios estabelecidos em pilares pedagógicos, didáticos, psicológicos, sociológicos, filosóficos, políticos e legais que refletem as pesquisas, as teorias e 
as necessidades educacionais. Evidente que a assimilação desses princípios demanda muito conhecimento sobre a função social da escola. Vale aqui lembrar a insuficiente formação dos professores nas áreas citadas, o que fará com que o Professor Coordenador encontre na escola muitas opinióes de senso comum, com uma reflexão pouco sistematizada sobre a educação pública. Entretanto, não é hora de antagonismos. A capacitação em serviço e as várias açóes previstas pela SE procurarão ajudálo a superar esse caráter formativo do professor. O Professor Coordenador deve lembrar-se de sua função cooperativa e colaboradora na relação com os professores. (SEE-SP, 2008b, p. 31).

É inevitável entender que a expectativa da Secretaria da Educação é a de que o Professor Coordenador desempenhe um papel de alguém que tenha se apropriado integralmente da Proposta, aceite-a e a defenda, para assim poder difundi-la na escola, já que lhe cabe a atribuição de garantir que os professores também conheçam, aceitem e objetivemna na prática escolar. Em resumo, o Professor Coordenador é elevado à condição de principal responsável por garantir que a reforma, concebida autoritariamente nos órgãos centrais do aparelho burocrático de Estado, se transforme em prática concreta na escola. Esta é, sem dúvida, uma nova concepção para a função do Coordenador Pedagógico, ainda mais se considerarmos que pouco, ou quase nada, se atribuiu ao Supervisor de Ensino e ao Diretor Escolar no processo de implantação de reforma. A tradição na rede pública estadual de São Paulo em relação aos resultados produzidos pelos “Coordenadores", em suas inúmeras denominaçóes, nos faz suspeitar que confiar o sucesso da reforma à quase exclusiva atuação dos Professores Coordenadores pode ser uma estratégia de alto risco.

A adoção de um currículo único e padronizado, que expressa direcionamentos claros, inclusive de "métodos e estratégias de trabalho" para os professores, parece divergir de princípios constitucionais regulamentados pela LDB 9.394/96 que estabelece a "pluralidade de concepçóes pedagógicas" para a educação nacional, a autonomia da escola para produzir sua proposta pedagógica, a gestáo democrática, a participaçáo dos professores e da comunidade (colegiados) na concepção do projeto políticopedagógico. 
No entanto, quanto à legalidade da Proposta Curricular, a Secretaria Estadual de Educação justifica seu posicionamento no Caderno do Gestor afirmando que existe pouca compreensão do aspecto legal da LDB 9.394/96 que trata da autonomia dos estabelecimentos de ensino na determinação da sua Proposta Pedagógica. A autonomia das escolas seria relativa e a Proposta Curricular do Programa "São Paulo faz escola" seria um dos seus limitadores, uma vez que, nesta perspectiva, as escolas devem seguir as regras dos sistemas de ensino ao qual estão subordinadas, neste caso, ao Sistema Estadual de Ensino. Mais uma vez, de passagem, parece lícito pensar, pelo argumento da Secretária da Educação, que ela não distingue entre rede escolar e sistema de ensino.

Ainda como parte da reforma o Programa de Qualidade da Escola foi lançado em maio de 2008 pela SEE-SP, para avaliar anualmente cada escola da rede estadual paulista, por meio do Índice de Desenvolvimento da Educação do Estado de Sáo Paulo (IDESP), e propor metas para o aumento dos índices de qualidade do ensino. De acordo com a nota técnica da SEE-SP, o IDESP é um indicador composto por dois critérios de avaliação da qualidade da escola. De um lado, mede o desempenho dos alunos nos exames do Sistema de Avaliaçáo do Rendimento Escolar do Estado de Sáo Paulo (SARESP), que avalia quanto os alunos aprenderam das competências e habilidades requeridas para a sua série; e de outro, o fluxo escolar, que avalia se estes aprenderam dentro de um ano letivo, o período de tempo considerado ideal.

Nesta mesma nota técnica, a SEE-SP apresenta as formas de cálculo do IDESP e do Índice de Cumprimento de Metas e do Adicional por Qualidade (IQ), que normatizam o pagamento do bônus por resultado. Nela se afirma que qualquer avanço no IDESP de um ano para o outro é bonificado, sendo esta gratificação proporcional à parcela cumprida da meta estabelecida para a escola.

Sobre as políticas de remuneração por desempenho, uma das estratégias fundamentais da reforma em pauta, Ball (1994) afirma que elas permitem o controle e monitoramento pelas instâncias político-administrativas da prática dos professores e das escolas, ao compará-las pelo desempenho do aluno. Outro ponto importante que o autor nos revela sobre essa modalidade de incentivos é a sua tendência de desumanização e despersonificaçáo do professor que passa a ser um executor de tarefas. 
Segundo o Caderno do Gestor, os resultados do SARESP, que fazem parte da composição do IDESP, são importantes indicadores da qualidade do ensino oferecido na unidade escolar e que o SARESP (avaliaçáo estadual) permite a comparação de seus resultados com os obtidos no SAEB e na Prova Brasil (avaliaçôes nacionais), por se valer da mesma escala de medição de desempenho. Cabe lembrar que em 2008, os níveis de desempenho passaram a ser interpretados pedagogicamente à luz da Matriz de Referência do SARESP e do Novo Currículo do Estado de Sáo Paulo.

A unificação do currículo é apresentada como o alicerce que permitiu a estruturação da avaliação em larga escala. A SEE-SP (2009a, p. 52) afirma no Caderno do Gestor que

Os objetivos de desempenho estão agora descritos, por meio de uma série de critérios do rendimento esperado, de forma a constituir a estrutura básica de um sistema de avaliação referenciado a esses critérios, que incentiva os professores a se concentrarem nas habilidades e nos processos estabelecidos, para que os alunos os desenvolvam.

A esse respeito, os resultados da pesquisa aqui apresentada revelam

\section{A apropriaçáo da proposta curricular na prática escolar}

Neste item, apresentamos a discussão de alguns aspectos destacados pela pesquisa, especialmente aqueles com foco na apreensão que se pode 
ter da apropriação que os professores da Língua Portuguesa fazem dos princípios e ideias centrais da reforma proposta pelos dirigentes da educação paulista.

A SEE-SP propóe, em Língua Portuguesa, o trabalho centrado nos gêneros textuais por entender que esta organizaçáo dos conteúdos de Língua Portuguesa, para o ciclo II do Ensino Fundamental, possibilita que o alu no aprenda a lidar com textos nas diferentes situaçôes de interação social, ou seja, amplia sua habilidade de "[...] interagir linguisticamente por meio de textos, nas situaçóes de produção e recepção em que circulam socialmente, que permite a construção de sentidos desenvolvendo a competência discursiva e promovendo o letramento [...]" (SEE-SP, 2008a, p. 43, grifo da autora). O nível deste letramento, segundo a Proposta Curricular para Língua Portuguesa, é evidenciado pela variedade de gêneros textuais que os alunos reconhecem.

Embora a implementação da Proposta Curricular, em 2008, tenha interferido diretamente na prática de elaboração dos Planos de Ensino da escola pesquisada, determinando seu conteúdo, eles não apareceram como norteadores do trabalho docente nas entrevistas com os professores de Língua Portuguesa. Não foram mencionados pelos professores quando perguntados sobre como realizam o planejamento das suas aulas. Os dados indicaram, também, que a prática de planejamento instituída entre os professores é guiada principalmente pelas atividades estabelecidas nos Cadernos do Aluno que pelos objetivos de aprendizagem, ou competências e habilidades a serem desenvolvidas no aluno, ou, ainda, pela descrição da situação de aprendizagem apontada nos Cadernos do Professor.

Os dados são enfáticos na revelação de que os docentes de Língua Portuguesa da escola pesquisada fizeram uma apropriação que se distancia das ideias e concepçôes que fundamentaram a proposta dos reformadores, segundo o discurso destes ao exporem e justificarem a reforma. Além de reduzir o planejamento de ensino à adoçáo dos Cadernos do Aluno e à realização das atividades que propóem, entendem os professores que trabalhar com a proposta se restringe a fazer uso dos mesmos na sala de aula. Em reforço a esta conclusão, estes declaram que não trabalham com a proposta nas aulas de Produção de Texto, parte diversificada do currículo, porque para esta disciplina não existem Cadernos, ou apostilas, como usualmente se referem àquele material, ou seja, os professores não relacionam o desen- 
volvimento de habilidades e competências com sua prática nas aulas de Produção de Texto.

Com relação aos oito princípios centrais destacados nos documentos - a escola que aprende; o currículo como espaço de cultura; as competências como eixo de aprendizagem; a prioridade da competência de leitura e de escrita; a articulaçáo das competências para aprender; e a contextualização no mundo do trabalho (SEE-SP 2008a, p. 11) - apenas o desenvolvimento de habilidades e competências foi citado pelos docentes. Nenhum dos professores entrevistados fez referência a quaisquer dos outros sete princípios enumerados durante todas as entrevistas ou nos momentos de conversas informais deles com os pesquisadores.

Ficou evidente que os professores não têm clareza sobre os conceitos de competências e habilidades, que fundamentam o reforma em pauta, e que usam aqueles termos frequentemente esvaziados de significação. Os exemplos citados pelos professores nas entrevistas sobre as atividades desenvolvidas em Língua Portuguesa revelam diferentes níveis de consciência destes docentes sobre a apropriaçáo do conceito de desenvolvimento de competências e habilidades em sua prática e estes perdem, assim, o sentido que lhe atribuíram os formuladores da proposta curricular.

No Caderno do Professor são apresentadas as expectativas de aprendizagem e uma grade de avaliação na qual são elencados parâmetros para a avaliaçáo do aluno, descrevendo o que os alunos devem ser capazes de fazer ao final do caderno do bimestre. Neste item são colocadas perguntas para que o professor reflita sobre a aprendizagem dos seus alunos durante as sequências de atividades, exercícios de sistematização e em todas as avaliaçôes realizadas.

A finalidade da avaliação, segundo a proposta, é auxiliar o professor na sua reflexão sobre os aspectos que precisam ser repensados ou planejados para sua próxima aula. Os Cadernos do Professor de Língua Portuguesa propóem a verificação das competências e das habilidades em um processo contínuo de avaliação, no desenvolvimento das atividades, na participação e na produção dos alunos e em uma avaliaçáo pontual.

Para esta avaliação pontual recomenda-se uma prova individual ou qualquer outro instrumento de eleição do professor, mas os Cadernos apresentam uma sugestão pronta de prova para o respectivo bimestre, com tex- 
tos, perguntas de múltipla escolha e dissertativas para serem usadas pelos docentes na avaliação da aprendizagem dos alunos.

Entretanto, um ponto bastante confuso para os professores é a diferenciação de avaliação processual de prova individual. Nas falas, fica evidente a dúvida com relação à aplicação de provas individuais: alguns acreditam que não se possa dar prova individual, só em grupo, ou que só podem aplicar para nota individualmente trabalhos e não provas.

Um exemplo disso é a significaçáo que a proposta de avaliaçáo processual adquiriu no contexto da sala de aula, revelada no relato dos professores sobre suas práticas avaliativas. Os professores afirmam fazer a verificação sistemática da produção continuada de seus alunos e da participação destes nas atividades, porém náo realizam registros das dificuldades ou dos progressos na aprendizagem dos alunos. Na prática, o que ocorre é apenas a verificação do cumprimento ou não das tarefas solicitadas.

Constatamos que ainda permanece a concepção de avaliação pontual e classificatória, mesmo que se afirme estar avaliando processualmente, a prática relatada se revela pontual, quer por provas ou trabalhos, individuais ou em grupos. $\mathrm{O}$ que se tem posto em prática na verdade se revela como um aumento da frequência de avaliaçóes pontuais com o objetivo de proporcionar mais oportunidades para que os alunos acumulem notas (baseada em uma norma pré-estabelecida).

Com tudo isso, a avaliação, como instrumento de reflexão sobre o planejamento da prática ou da recuperação continuada da aprendizagem, se perde na concepção de aprovação automática dada pelos professores para a progressáo continuada.

\section{Consideraçóes finais}

Os dados revelaram que, para os professores, as estratégias de apresentação da proposta utilizadas pela Secretaria da Educação tiveram pouca importância para determinar como os docentes iriam se apropriar delas. De certa forma esses dados contrariam as nossas

expectativas, e cremos dos reformadores, posto que houve um forte investimento naquele processo com a produção maciça de materiais em forma de videoconferências e vídeos instrucionais, com a participação de 
educadores de renome para a produção do discurso justificador e para sua credibilidade.

Já o protagonismo atribuído ao Professor Coordenador Pedagógico que entendemos existir nesta reforma, não foi apreendido como tal pelos docentes de Língua Portuguesa e nem sequer pelo próprio professor coordenador.

Por outro lado, a padronização do material didático praticamente naturalizou a aceitação e a implementaçáo da proposta, tendo sido apropriada pela escola como uma necessidade de unificaçáo do currículo na rede pública de ensino. Considerando a intenção da SEE-SP de criar consensos sobre os pontos teóricos da proposta curricular, com relação à unificação do currículo esse objetivo foi seguramente atingido, ainda que por uma compreensão equivocada do seu sentido e significado por parte dos docentes, na medida que aceitam a unificação e padronização curricular como uma estratégia de superação do quadro de total inexistência de um projeto pedagógico para a rede escolar e das condiçóes gerais de trabalho que dificultam a construção coletiva de projetos político-pedagógicos pelas unidades escolares, o que configura um ato de astúcia política dos professores diante da imposição autoritária de uma reforma para a qual não foram ouvidos.

\section{Referências}

BALL, Stephen J. Education reform: a critical and post structural approach. Buckingham, UK: Open University Press, 1994.

FARIA FILHO, Luciano Mendes de. Escolarização e cultura escolar no Brasil: reflexões em torno de alguns pressupostos e desafios. In: BENCOSTA, Marcus Levy Albino (Org.). Culturas escolares, saberes e práticas educativas: itinerários históricos. São Paulo: Cortez, 2007.

LOPES, Alice Casimiro. Políticas curriculares: continuidade ou mudança de rumos? Revista Brasileira de Educação, Rio de Janeiro, n. 26, p. 109-118, ago. 2004.

POPKEWITZ, Thomas S. Reforma educacional: uma política sociológica - poder e conhecimento em educação. Porto Alegre: Artes Médicas, 1997.

SACRISTÁN, J. Gimeno. O currículo: uma reflexão sobre a prática. Porto Alegre: Artmed, 2000. 
SÁNCHEZ VÁZQUEZ, Adolfo. Filosofia da práxis. Tradução María Encarnación Moya. Buenos Aires: CLACSO; São Paulo: Expressão Popular, 2007.

SÃO PAULO. Proposta Curricular do Estado de São Paulo: Língua Portuguesa. FINI, Maria Inês (Coord.). São Paulo: SEE, 2008(a).

. Caderno do Gestor. Gestão do currículo na escola. v. 1. MURRIE, Zuleika de

Felice. São Paulo: SEE, 2008(b).

. Caderno do Gestor. Gestão do currículo na escola. v. 2. MURRIE, Zuleika de

Felice. São Paulo: SEE, 2009(a).

Caderno do Professor: Língua Portuguesa, Ensino Fundamental $-5^{\mathrm{a}}$ a $8^{\mathrm{a}}$ série. v. 1, 2, 3 e 4. São Paulo: SEE, 2009(b).

. Caderno do Aluno: Língua Portuguesa, Ensino Fundamental - 5a a $8^{\mathrm{a}}$ série. v. 1, 2, 3 e 4. São Paulo: SEE, 2009 (c).

SILVA JR. João dos R.; FERRETTI, Celso João. O institucional, a organização e a cultura da escola. São Paulo: Xamã. 2004.

VIÑAO FRAGO, Antonio. Sistemas educativos, culturas escolares y reformas. 2. ed.

Madri: Morata, 2006.

Recebido em 3I out. 20I / Aprovado em 24 dez. 20 I I

\section{Para referenciar este texto}

SILVA, V. A.; RUSSO, M. H. Reforma educacional e prática docente: o discurso sobre a apropriação dos seus fundamentos na escola. EccoS, São Paulo, n. 26, p. 9I-IO5, jul./dez. 20 II. 
